\title{
A Modelling Approach to Develop Machine Smoking Protocols Reflecting Human Puffing Behaviour for Conventional Cigarettes*
}

\author{
by \\ H.-Jörg Urban ${ }^{1}$, Willy Gomm², and Matthias Schorp ${ }^{l}$ \\ ${ }^{1}$ Philip Morris International, Philip Morris Product SA, Research \& Development, Quai Jeanrenaud 56, \\ 2000 Neuchâtel, Switzerland \\ ${ }^{2}$ Philip Morris Research Laboratories GmbH, Fuggerstr.3, D-51149 Cologne, Germany
}

\section{SUMMARY}

Our objective was to develop machine-smoking protocols (i.e. puff volume, puff duration and puff frequency) reflecting the distribution of human smoking behaviour as a complement to the International Standard (ISO) protocol. For this purpose, a modelling approach based on smoking topography and excretion data of urinary nicotine metabolites from clinical studies in the UK and Japan was used. Three smoking protocols (LOW, MEDIUM and HIGH) were based on the 10th percentile, the mean and the 90th percentile of the puff volumes obtained from topography data. The corresponding puff durations were estimated by linear regression analysis of the puff duration/puff volume relationship. Finally, puff frequency was estimated using a predictive model assuming that the nicotine yield is a linear function (i.e. proportional) to the amount of air actually drawn through the burning part of the cigarette. This approach was termed "nicotine proportion method" where the puff frequency is changed iteratively until it equals the corresponding nicotine uptake measured in human smokers during a clinical study. The assumption was verified by measuring the nicotine yield in the laboratory on three modelled protocols for four conventional cigarettes. In 10 out of 12 cases, a very good agreement was observed between the estimated nicotine yields obtained with our modelling approach and the measured nicotine yields obtained from smoking machines in the laboratory.

Although smoking virtually identical cigarettes, smoking protocols based on topography and excretion data of urinary nicotine metabolites from the UK clinical study were different than those based on data from the study performed in Japan. This may be explained by different smoking behaviour between these two populations of smokers. [Beitr. Tabakforsch. Int. 23 (2008) 8-18]

\section{ZUSAMMENFASSUNG}

Das Ziel dieser Studie ist es, als eine Ergänzung zum ISOProtokoll, alternative Rauchmaschinen-Protokolle (d.h. Zugvolumen, Zugdauer und Zughäufigkeit) zu entwickeln, die dem menschlichen Rauchverhalten entsprechen. $\mathrm{Zu}$ diesem Zweck wurde ein Modellierungsansatz entwickelt, der auf Daten zur Rauch-Topographie sowie Urin-Nikotin Metaboliten aus klinischen Studien (aus Japan und Großbritannien) basiert.

Drei Abrauchprotokolle (LOW, MEDIUM und HIGH) entsprechen dem 10., dem Mittelwert und dem 90. Percentil des Zugvolumens, die mit Hilfe von topographischen Daten berechnet wurden. Die jeweils entsprechende Zugdauer wurde mit Hilfe linearer Regressionsanalysen aus der Zugdauer/Zugvolumen Beziehung bestimmt. Unter der Annahme, dass der Nikotingehalt sich proportional zum Anteil der Luft (die durch den Glutkegel der Zigarette gezogen wird) verhält, wurde die Zughäufigkeit mit einem mathematischen Vorhersage-Modell iterativ berechnet. Der als ,nicotine proportion-method" bezeichnete Ansatz wurde kalibriert, indem die Zughäufigkeit iterativ geändert wurde, bis sie der im Modell berechneten Nikotinaufnahme entsprach, die bei Rauchern in klinischen Studien bestimmt worden war. Das Modell wurde verifiziert, indem der Nikotingehalt im Labor für drei modellierte Abrauchprotokolle an vier konventionellen Marktzigaretten bestimmt wurde. In 10 von 12 Fällen konnten sehr gute Übereinstimmungen zwischen dem mit Hilfe des Modellierungsansatzes berechneten Nikotingehalt und dem im Labor mit Hilfe von Abrauchmaschinen gemessenen Nikotingehalt gefunden werden.

Obwohl sich die Zigaretten kaum unterschieden, wurden Unterschiede bei den Abrauchprotokollen zwischen Großbritannien und Japan festgestellt. Dies könnte durch 
unterschiedliches Rauchverhalten bei den beiden unterschiedlichen Raucher-Populationen erklärt werden. [Beitr. Tabakforsch. Int. 23 (2008) 8-18]

\section{RESUME}

L'objet de cette étude est le développement de protocoles de fumage complémentaires de la méthode normalisée ISO (i.e. volume de bouffée, durée de bouffée, fréquence de bouffée), reflétant le fumage humain. Dans ce but, une approche de modélisation basée sur la topographie du fumage et l'excrétion des métabolites de la nicotine urinaire lors d'études cliniques réalisées au Royaume-Uni et au Japon a été utilisée. Trois protocoles de fumage (LOW, MEDIUM, HIGH) correspondent au 10ème, au niveau médian et au 90ème centile des volumes de bouffée calculés par des données topographiques. Les durées des bouffées correspondantes ont été estimées par analyse de régression linéaire du rapport durée/volume de bouffée. De plus, la fréquence de bouffée a été estimée à l'aide d'un modèle prédictif, en supposant que la teneur en nicotine est en fonction linéaire (i.e. proportionnelle) avec l'air aspiré à travers le cône de combustion de la cigarette. Dans cette approche, appelée «nicotine proportion method», la fréquence de bouffée est changée itérativement lorsqu'elle correspond à l'absorption de la nicotine d'un fumeur humain dans une étude clinique. L'hypothèse a été vérifiée par la mesure au laboratoire des teneurs en nicotine de quatre cigarettes conventionnelles selon trois protocoles modélisés. Dans 10 sur 12 cas les teneurs en nicotine estimées à l'aide de cette approche de modélisation sont en bon accord avec les teneurs en nicotine obtenues au laboratoire par des machines à fumer.

Même si les cigarettes sont pratiquement identiques, des différences dans les protocoles de fumage ont été constatées entre l'étude clinique au Royaume-Uni et au Japon. Cet effet pourrait être expliqué par un comportement au fumage différent entre ces deux populations. [Beitr. Tabakforsch. Int. 23 (2008) 8-18]

\section{INTRODUCTION}

For more than 40 years, testing laboratories have generated cigarette smoke using the Federal Trade Commission's (FTC) standardized machine-smoking protocol $(25,26)$, or the almost identical International Standards Organization (ISO) method (17). The purpose of these protocols was to provide comparative information about the amount of smoke constituents in different brands of cigarettes $(3,11)$. Both smoking protocols specify that cigarettes are machine smoked with a puff volume of $35 \mathrm{~mL}$, a puff duration of $2 \mathrm{~s}$ and a puff interval of $60 \mathrm{~s}$. For a comparison between the two protocols ${ }^{\mathrm{a}}$ refer to RUSTEMEIER and PIADÉ (30). Use of these protocols to generate smoke yields over the years ". . . created the belief in some that data obtained with this protocol were intended to predict nicotine uptake by smokers" $(8,9)$. However, numerous smoking behaviour studies report significant differences between smoke yields

\footnotetext{
a In the following the "ISO/FTC protocol" will be referred to as "ISO protocol"
}

obtained from ISO machine smoking and smoke constituents uptake $(2,4,5,13,21,27,29)$ indicating that smoke yields obtained using the ISO smoking protocol may not reflect the uptake of smoke constituents by smokers $(18,34)$, because "no two smokers smoke exactly the same nor does a smoker smoke a cigarette the same way on every occasion" (3). Due to the wide range of human smoking behaviour, where smokers can adapt their smoking behaviour by altering the principal puffing variables (e.g. puff volume, puff duration, puff interval, and puff count), no single machine smoking protocol can reflect human puffing parameters (smoking topography), and cigarettes may be smoked differently than the parameters specified by the ISO smoking protocol $(6,7,20,22,23,33,35)$.

Several studies using different approaches have investigated human puffing behaviour to enable the estimation of mainstream constituent's intake by human smokers. Basically, two approaches have been applied:

a) Indirect measurement of the puffing behaviour by quantification of solanesol or nicotine retained by the filter during smoking and relating this amount to the mainstream solanesol (or nicotine) yield (32).

b) Direct measurement using smoking topography devices placed between the cigarette and the smoker. This method records smoking topography (e.g. puff volume and puff duration) and thus estimates human puffing behaviour. An example for such a device is the CReSSMicro $^{\mathrm{TM}}$ from Plowshare ${ }^{\circledR}$ Technologies, Inc., (Baltimore, MD) $(1,14,31)$.

In this paper our primary objective was to develop and describe a method allowing the determination of smoking protocols which would reflect a range of human smoking behaviour. Taking into account the large inter- and intraindividual variability of human smoking behaviour, any single protocol would be no more than another point estimate (similar to the ISO protocol) reflecting only the behaviour of a certain percentage of a certain population. On the other hand, for a population of human smokers, the combination of all smoking topography variables (puff volume, puff duration, puff frequency, etc.) represents a continuum of possible smoking protocols within a multidimensional parameter space. For technical and feasibility reasons, most studies can only be carried out with a limited number of smoking protocols.

Thus, we wanted to select a minimal set of smoking protocols that meaningfully reflect the distribution of smoke exposure of mainstream smoke (MSS) constituents by a population, taking into account both, measured smoking topography, as well as nicotine uptake of that population. Additionally, the applicability of the model was compared between two populations of different ethnic origin.

\section{DATA SOURCES AND DATA HANDLING}

Data were taken from two studies on adult smokers conducted in the UK and in Japan. The objective of these studies was to determine whether certain biomarkers of exposure were significantly lower in adult smokers of a "Test Cigarette" (6 mg ISO 'tar') as compared to smokers of two different market cigarettes and to compare the three 
Table 1. Cigarette design parameters and ISO yields for M6UK, M6Ja, PM1 and LARK1

\begin{tabular}{|c|c|c|c|c|c|}
\hline \multirow[b]{2}{*}{ Cigarette design parameters } & \multirow[b]{2}{*}{ Units } & \multicolumn{4}{|c|}{ Averages } \\
\hline & & M6UK & M6Ja & PM1 & LARK1 \\
\hline Butt length & $(\mathrm{mm})$ & 35.0 & 35.0 & 35.0 & 35.0 \\
\hline Cigarette length & $(\mathrm{mm})$ & 84.0 & 84.0 & 84.0 & 83.0 \\
\hline Filter length & $(\mathrm{mm})$ & 27.0 & 25.0 & 27.0 & 27.0 \\
\hline Tipping length & $(\mathrm{mm})$ & 32.0 & 32.0 & 32.0 & 32.0 \\
\hline Ventilation $(D)$ & $(\%)$ & 45 & 45 & 74 & 78 \\
\hline Tobacco weight & $(\mathrm{mg})$ & 612 & 655 & 530 & 603 \\
\hline Static burn time & $(\min )$ & 7.4 & 6.4 & 7.2 & 6.5 \\
\hline \multicolumn{6}{|c|}{ Yields and conditions for the ISO protocol } \\
\hline Puff count & $\left(n \operatorname{cig}^{-1}\right)$ & 8.4 & 7.8 & 7.9 & 8.9 \\
\hline TPM & $\left(\mathrm{mg} \mathrm{cig}{ }^{-1}\right)$ & 8.07 & 8.08 & 1.77 & 1.37 \\
\hline 'Tar' & $\left(\mathrm{mg} \mathrm{cig}{ }^{-1}\right)$ & 6.65 & 6.64 & 1.46 & 1.12 \\
\hline Nicotine & $\left(\mathrm{mg} \mathrm{cig}{ }^{-1}\right)$ & 0.54 & 0.48 & 0.15 & 0.10 \\
\hline
\end{tabular}

groups to a no-smoking group. The major difference between the UK and Japanese studies were the market cigarettes used. In the UK study, Marlboro cigarettes (M6UK, $6 \mathrm{mg}$ ISO 'tar') and Philip Morris One (PM1, $1 \mathrm{mg}$ ISO 'tar') were used while in the Japanese study, (M6Ja, 6 mg ISO 'tar') and Lark One (LARK1, $1 \mathrm{mg}$ ISO tar) were used. For both studies the experimental design was similar:

Subjects were enrolled in a two days acclimatization period during which all subjects smoked Marlboro filter cigarettes. Then 100 subjects ( 50 males and 50 females) were randomized into 4 groups (40 in the TEST group, and 20 each in the M6UK/M6Ja, the PM1/LARK1, and the no-smoking groups). After randomization, smokers continued smoking their assigned cigarette for 8 days.

Urinary nicotine and nicotine metabolites (cotinine, trans3 '-hydroxycotinine, nicotine- $N$-glucuronide, cotinine- $N$ glucuronide, and trans-3'-hydroxycotinine- $O$-glucuronide) were determined. The molar sum of nicotine and the five major metabolites excreted over 24 hours was defined as nicotine equivalents (Neq $\mathrm{mg} / 24 \mathrm{~h}$ urine) (28).

Cigarettes were smoked using CReSSMicro ${ }^{\mathrm{TM}}$ (Plowshare Technologies, Inc., Baltimore, MD), a battery-operated portable device that measures a full set of smoking topography variables (puff volume, puff number, puff duration, average flow, interpuff interval, time, and date). The device is small enough to allow independent use in the participant's natural environment. A cigarette is placed in a flowmeter mouthpiece, while the participant puffs on the cigarette through the end of the sterilized mouthpiece. A pressure transducer attached to the mouthpiece measures pressure changes that occur during inhalation. The pressure changes are amplified, digitized and a software converts the signal to airflow $(\mathrm{mL} / \mathrm{s})$ in real time $(\mathrm{s})$, generating data on number of puffs taken on the cigarette, puff volume, puff duration, maximum flow, and interpuff interval (time between puffs) are provided $(1,14,31)$. All subjects were instructed how to use the device during the acclimatization phase of the study. On Days 1 through 8, the CReSSmicro ${ }^{\mathrm{TM}}$ was used to gather smoking topography data (i.e., number of puffs, puff volume, puff duration, inter-puff interval, and peak flow) when smoking the first cigarette of the day and the first after lunch.

The cigarettes used in both studies were smoked under ISO conditions to obtain mainstream smoke nicotine yield.
These results are given in Table 1. Cigarette design parameters, such as cigarette length, tobacco weight, etc. are also presented in Table 1. For validation purposes, conditioned cigarettes were smoked with every experimental protocol using a 20-port Borgwaldt smoking machine. Nicotine yields were determined and were compared with the modelled yields (see Eqn. [3] below). These measurements were carried out at Philip Morris Research Laboratories $\mathrm{GmbH}$, Cologne, Germany.

Only data from the cigarettes M6UK, M6Ja, PM1 and LARK1 were used in this study.

Urine nicotine equivalents represent a major fraction of total nicotine uptake [approximately $80 \%$, (9)] and thus, require an adjustment for the fact that not all nicotine is accounted for by the measurements. Therefore, all nicotine equivalent data were multiplied with the adjustment factor of 1.25 and expressed as average milligrams of nicotine excreted per cigarette smoked. Mean total puff volume per cigarette was calculated as the sum of each puff for the cigarettes smoked using the topography device divided by the number of cigarettes smoked.

Data analysis consisted of fitting normal distributions to topography data arranged as frequency data as well as linear regressions analysis. For this purpose SAS statistical software Vers. 9.1.3. (SAS Institute, Cary, NC) was used. Results from these analyses were descriptive parameters of the normal distributions (mean, the $10^{\text {th }}$ and the $90^{\text {th }}$ percentiles) and regression parameters.

\section{RESULTS}

As a starting point and as a representative range, the human puffing behaviour was based on the mean, the $10^{\text {th }}$, and the $90^{\text {th }}$ percentiles of analyzed data distributions. Thus, three smoking protocols were defined and referred to as LOW (based on the $10^{\text {th }}$ percentile), MEDIUM (based on the mean) and HIGH (based on the $90^{\text {th }}$ percentile) of analyzed distributions. Throughout this document, smoking topography variables corresponding to any of these three protocols derived from human puffing behaviour are described with the subscript "hum" (e.g. puff volume hum $_{\text {) }}$, contrary to ISO smoking conditions where the subscript "ISO" was used (e.g. puff volume ${ }_{\text {ISO }}$ ). 
The determination of the smoking protocols (i.e. puff volume, puff duration, and puff frequency of the LOW, MEDIUM, and HIGH protocols) follows a four steps approach using different data sources. These four steps are outlined in Figure 1 and will be explained more detailed below.

\section{Step 1, Nicotine uptake distributions}

Owing to the fact that the biomarkers used to measure nicotine uptake from urinary excretion data are very specific, the method used for the modelling of the smoking protocols, was adjusted for nicotine. In other words, the smoking protocols were based on nicotine uptake ranges of human smokers. Thus, normal distributions were fitted to nicotine uptake data obtained from the determination of nicotine equivalent excretion in urine samples (Figure 2, Table 2, "nicotine target" values). These nicotine uptake distributions were later used to calculate the puff frequencies (see Step 4).

\section{Step 2, Determination of puff volume}

Normal distributions were fitted to mean puff volumes (Figure 3 ). From these distributions the $10^{\text {th }}$ percentile value was selected as the final puff volume for the LOW protocol, the $90^{\text {th }}$ percentile value for the HIGH protocol, and the mean value for the MEDIUM protocol, respectively. The final puff volumes for the three protocols of the four cigarettes are given in Table 2.

\section{Step 3, Determination of puff duration}

A clear linear relationship between puff duration and puff volume can be observed (Figure 4). This implies that one of these two variables can be estimated from the other by linear regression analysis. Puff duration was used as the dependent variable and determined as a function of puff volume (Eqn. [1]).

$$
\overline{P_{\mathrm{d}}}=a+b \cdot \overline{P_{\mathrm{v}}}
$$

where

$$
\begin{aligned}
& \overline{P_{\mathrm{d}}}=\text { mean puff duration }\left(\mathrm{s} \mathrm{cig}^{-1}\right) \\
& P_{\mathrm{v}}=\text { mean puff volume }\left(\mathrm{mL} \mathrm{cig}^{-1}\right)
\end{aligned}
$$

Since the linear regressions of the individual cigarettes (M6UK, M6Ja, PM1 and LARK1) were not significantly different (ANCOVA, $p>0.05$ ), data for all cigarettes were pooled. The corresponding puff durations for the puff volumes of the three protocols were based on the linear regression equation and the regression parameters ' $a$ ' and ' $b$ '. The final puff durations for the three protocols of the four cigarettes are given in Table 2.

\section{Step 4, Estimation of puff frequencies}

No simple relationship such as the linear relationship between puff volume and puff duration exists for the determination of the puff frequency. Thus, the estimation of puff frequencies followed a more complicated process where two equations (i.e. Eqns. [3] and [4]) were linked together and puff frequencies for every protocol were found iteratively. Corresponding target values (i.e. mean, $10^{\text {th }}$ and $90^{\text {th }}$ percentiles) of the nicotine uptake distributions (Step 1) were used as a goodness of fit criteria.

The "coal volume model" (12) reduces puff volume and number of puffs into a single variable (Eqn. [2]). The coal volume is defined as the volume of air drawn over the tobacco coal during the puffing of a cigarette and it is essentially independent of the puff interval:

$$
C_{\mathrm{v}}=\left(1-\frac{D}{100}\right) \cdot P_{\mathrm{c}} \cdot \overline{P_{\mathrm{v}}}
$$

where

$C_{\mathrm{v}}=$ coal volume $\left(\mathrm{mL} \mathrm{cig}^{-1}\right)$,

$D=$ ventilation $(\%)$ (a given constant depending on the design of the cigarette and vent blocking),

$P_{\mathrm{c}}=\operatorname{puff} \operatorname{count}\left(N \mathrm{cig}^{-1}\right)$,

$\overline{P_{\mathrm{v}}}=$ mean puff volume $\left(\mathrm{ml} \mathrm{cig.}^{-1}\right)$.

An extension of the coal volume model is the finding that smoke constituents yields such as nicotine are proportional to the coal volume. This implies that for a given ISO nicotine yield, the corresponding ISO coal volume and the coal volume of an "alternative" protocol (i.e. coal volume $\left._{\text {hum }}\right)$, the corresponding "alternative" nicotine yield (i.e. nicotine hum $_{\text {) }}$ can be estimated according to Eqn. [3]:

$$
\begin{aligned}
\text { nicotine }_{\text {hum }} & =\frac{\text { nicotine }_{\mathrm{ISO}} \cdot C_{\mathrm{v}_{\text {hum }}}}{C_{\mathrm{v}_{\mathrm{ISO}}}} \\
& =\frac{\text { nicotine }_{\mathrm{ISO}} \cdot\left[\left(P_{\mathrm{v}_{\text {hum }}} \cdot\left(1-\frac{D}{100}\right)\right) \cdot P_{\mathrm{c}_{\text {hum }}}\right]}{\left[\left(P_{\mathrm{v}_{\text {ISO }}} \cdot\left(1-\frac{D}{100}\right)\right) \cdot P_{\mathrm{c}_{\text {ISO }}}\right]}
\end{aligned}
$$

where

$C_{\mathrm{v}}=$ coal volume $\left(\mathrm{mL} \operatorname{cig}^{-1}\right)$,

$D=$ ventilation $(\%)$,

$P_{\mathrm{c}}=\operatorname{puff} \operatorname{count}\left(N \mathrm{cig}^{-1}\right)$,

$P_{\mathrm{v}}=$ puff volume $\left(\mathrm{mL}\right.$ puff $\left.^{-1}\right)$.

The following input data were used for Eqn. [3]: Puff volume $\left(P_{\mathrm{v}_{\mathrm{ISO}}}\right)$, puff count $\left(P_{\mathrm{c}_{\mathrm{SSO}}}\right)$ and nicotine yield (nicotine ${ }_{\text {ISO }}$ ) according to the ISO protocol determined in the laboratory (Table 1). Ventilation $(D)$ is a cigarette design parameter (Table 1). The puff volume $\left(P_{\mathrm{v}_{1}}\right)$ corresponding to human smoking conditions was determined according to Step 2. The remaining variable of Eqn. [3], i.e. puff count $\left(P_{\mathrm{c}_{\text {hum }}}\right)$ corresponding to human smoking conditions was estimated using Eqn. [4].

For a smoking machine protocol, puff count is set by the cigarette length and the remaining smoking topography variables (i.e. puff duration and puff frequency). However, puff counts have to be calculated as an input for Eqn. [3]: Mathematically, the puff count for any protocol can be estimated with Eqn. [4] provided the cigarette design parameters, topography data and the smoking conditions of the corresponding ISO protocol are known [Eqns. [4], [4a], [4b], [4c]): 


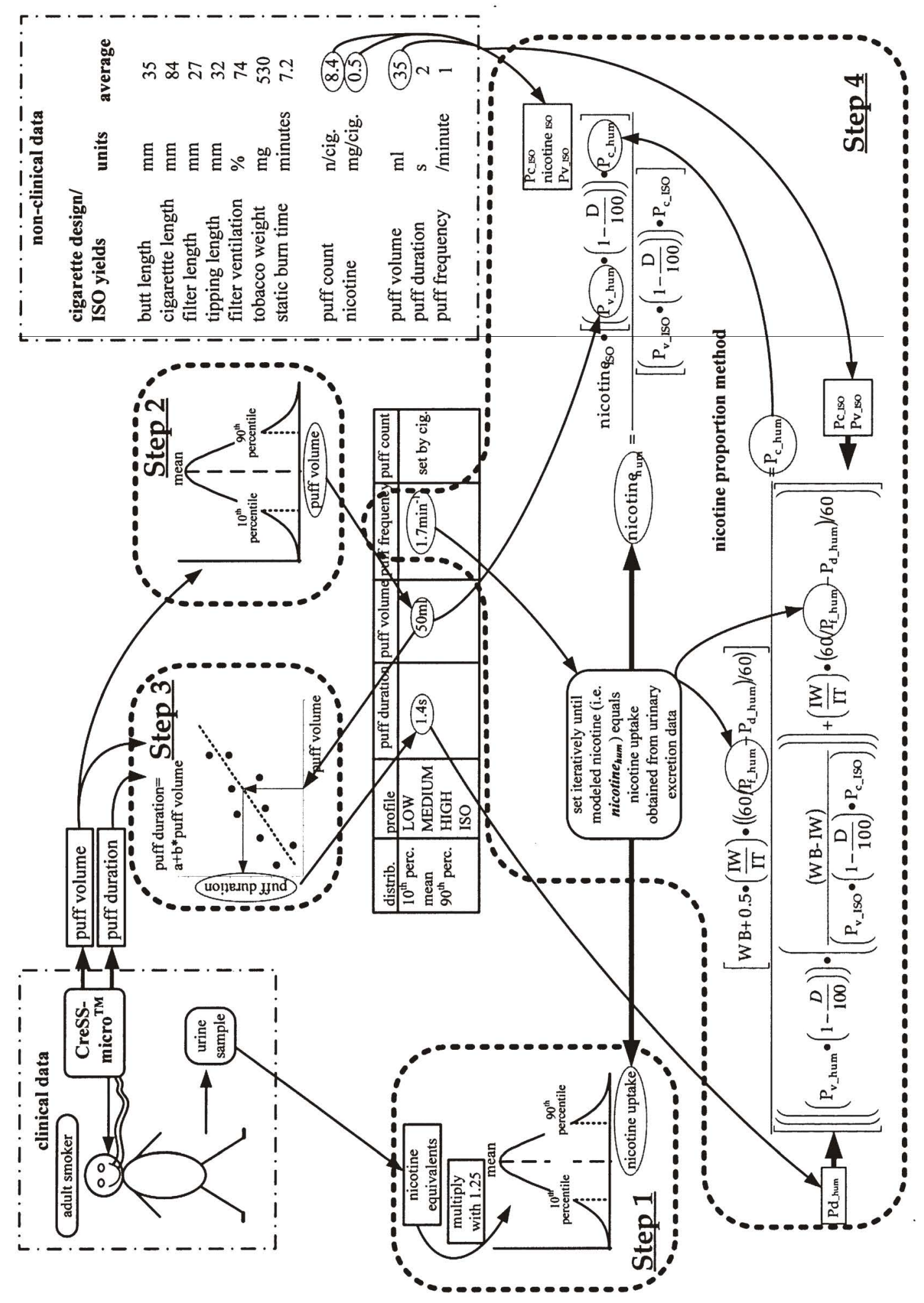

Figure 1. Outline for determination of smoking protocols (example for MEDIUM Protocol of M6UK; details see results; abbreviations see Eqns. [3] and [4]) 


$$
P_{\mathrm{c}_{\text {hum }}}=\frac{\left[\mathrm{WB}+0.5 \cdot\left(\frac{\mathrm{IW}}{\mathrm{IT}}\right) \cdot\left(\left(60 / P_{\mathrm{f}_{\text {hum }}}-P_{\mathrm{d}_{\text {hum }}}\right) / 60\right)\right]}{\left[\left(\left(( P _ { \mathrm { v } _ { \text { hum } } } \cdot ( 1 - \frac { D } { 1 0 0 } ) ) \cdot \left(\frac{(\mathrm{WB}-\mathrm{IW})}{\left.\left.\left.\left.\left(P_{\mathrm{v}_{\mathrm{ISO}}} \cdot\left(1-\frac{D}{100}\right) \cdot P_{\mathrm{c}_{\mathrm{ISO}}}\right)\right)\right]+\left(\frac{\mathrm{IW}}{\mathrm{IT}}\right) \cdot\left(60 / P_{\mathrm{f}_{\mathrm{hum}}}-P_{\mathrm{d}_{\mathrm{hum}}}\right) / 60\right)\right]}\right.\right.\right.\right.}
$$

$$
\begin{gathered}
\mathrm{WB}=(\mathrm{CL}-\mathrm{BL}) \cdot\left(\frac{\mathrm{TW}}{(\mathrm{CL}-\mathrm{FL})}\right) \\
\mathrm{IT}=\left(P_{\mathrm{c}_{\mathrm{ISO}}}-0.5\right) \cdot\left(\left(60 / P_{\mathrm{f}_{\mathrm{ISO}}}-P_{\mathrm{d}_{\mathrm{ISO}}}\right) / 60\right) \\
\mathrm{IW}=\mathrm{IT} \cdot\left(\frac{40}{\mathrm{SB}}\right) \cdot\left(\frac{\mathrm{TW}}{(\mathrm{CL}-\mathrm{FL})}\right)
\end{gathered}
$$

where

$P_{\mathrm{c}}=\operatorname{puff} \operatorname{count}\left(N \mathrm{cig}^{-1}\right)$,

$\mathrm{WB}=$ weight burned $(\mathrm{mg})$,

IT $=$ interval time $(\mathrm{min})$,

IW $=$ interval weight $(\mathrm{mg})$.

Cigarette design parameter:

$\mathrm{CL}=$ cigarette length $(\mathrm{mm})$,

$\mathrm{BL}=$ butt length $(\mathrm{mm})$,

$\mathrm{TW}=$ tobacco weight $(\mathrm{mg})$,

$\mathrm{FL}=$ filter length $(\mathrm{mm})$,

$\mathrm{SB}=$ static burn time (min),

$D=$ ventilation $(\%)$.

From ISO protocol:

$P_{\mathrm{c}_{\text {ISO }}}=$ puff count $\left(\mathrm{n} \mathrm{cig}^{-1}\right)$,

$P_{\mathrm{f}_{\mathrm{ISO}}}^{\mathrm{c}_{\mathrm{ISO}}}=$ puff frequency $\left(\mathrm{min}^{-1}\right)$,

$P_{\mathrm{d}_{\text {ISO }}}=$ puff duration $\left(\mathrm{s} \mathrm{cig}^{-1}\right)$.

Smoking conditions derived from human smoking behavior:

$P_{\mathrm{f}_{\mathrm{hum}}}=$ puff frequency $\left(\mathrm{min}^{-1}\right)$,

$P_{\mathrm{d}_{\text {hum }}}=$ puff duration $\left(\mathrm{s} \mathrm{puff}^{-1}\right)$,

$P_{\mathrm{v}_{\text {hum }}}^{\mathrm{d}_{\text {hum }}}=$ puff volume $\left(\mathrm{mL} \mathrm{puff}^{-1}\right)$.

Note: $P_{\mathrm{f}}$ was set iteratively (Step 4), $P_{\mathrm{d}_{\text {}}}$ was estimated with linear regression (Eqn. [2], SStep 3) and $P_{\mathrm{v}_{\text {hum }}}$ was estimated from normal distributions of puff volumes (topography data, Step 2). Design parameters for the 4 cigarettes are given in Table 1.

Eqns. [3] and [4] were then linked in a spreadsheet and puff frequencies were found iteratively until the estimated nicotine yields equalled the target nicotine uptake values (see Figure 1, Step 4). In other words, for a given puff frequency $\left(P_{\mathrm{f}_{\text {hum }}}\right)$ with Eqn. [4] the corresponding puff count $\left(P_{\mathrm{c}_{\text {hum }}}\right)$ was calculated. This puff count was used as input for Eqn. [3], which calculated the corresponding nicotine yield (nicotine $\mathrm{hum}_{\text {}}$ ). The puff frequencies were changed for every cigarette and protocol until the nicotine yield equalled the corresponding value from the nicotine uptake distribution (i.e. nicotine $_{\text {hum }}=$ nicotine uptake). Because Eqn. [3] is the key function in this approach, Step 4 was called "nicotine proportion method".

\section{Validation}

Nicotine yields obtained for the three experimental protocols in the laboratory are given in Table 2 ("nicotine measured"). Except for the cigarette PM1 at the MEDIUM and HIGH protocols, a very good agreement between modelled (Eqn. [3]) and measured yields was observed.

\section{DISCUSSION}

\section{Accuracy of the topography data}

Our model, and thus to a certain extent, the modeled protocols depend on the accuracy of the topography data obtained with the (CReSSMicro $\left.{ }^{\mathrm{TM}}\right)$. As the device is rather new little published information is available. To our knowledge, five reports $(1,14,15,19,31)$ where topography data were obtained with the CReSSMicro ${ }^{\mathrm{TM}}$ device have been published. Only HAMMOND et al. (14) mention checking for data accuracy: "Three independent raters coded for invalid data due to device misuse, device inaccuracies, and unrealistic values. The three raters agreed on $90 \%$ of all data points; all other data points were dropped from the analyses to ensure conservative standards for data quality." In the present study we checked the topography data by screening the puff volumes for unrealistic values, i.e. values which were unlikely to be achieved by human smokers for physiological reasons. Such selected data, which amounted to less than $5 \%$ of the data points were subsequently removed from the analysis.

Furthermore, laboratory measurements on calibrated smoking machines indicate some inaccuracies associated with the $\mathrm{CReSSMicro}^{\mathrm{TM}}$ device (personal communication, 16). The triggering of the device may not be instantaneous, i.e., a "threshold" exists, which artificially biases the recorded data: Depending on the "threshold" settings a potential for false puffs (when threshold settings are too low), or an underestimation of puff volumes (when threshold settings are too high) exists. Puff durations and puff volumes were underestimated at low flow rates (i.e. at less than $30 \mathrm{~mL} \mathrm{~s}^{-1}$ ), but to a lesser extent at higher flow rates. As a consequence, puffs with long duration and low flow rates were more likely to have under-reported volumes and durations. We concluded that the CReSSMicro ${ }^{\mathrm{TM}}$ device overestimates puff volume, throughout the entire range, by $5 \%$ and underestimates puff duration, throughout the entire range, by 400 to $600 \mathrm{~ms}$. Puff volume is most accurately measured in the mid-range of its output (about 55 to $70 \mathrm{~mL}$ ).

Generally, these findings could influence the modelled protocols in the following ways:

a) Puff volumes: For the estimation of the puff volumes, data are most accurate for the mid-range, thus, the estimation of MEDIUM protocol is not affected. For the LOW and HIGH protocols the puff volumes would be - as reported - overestimated by $5 \%$.

b) Puff durations: To demonstrate the effect of the device on the puff duration vs. puff volume relationship, data 

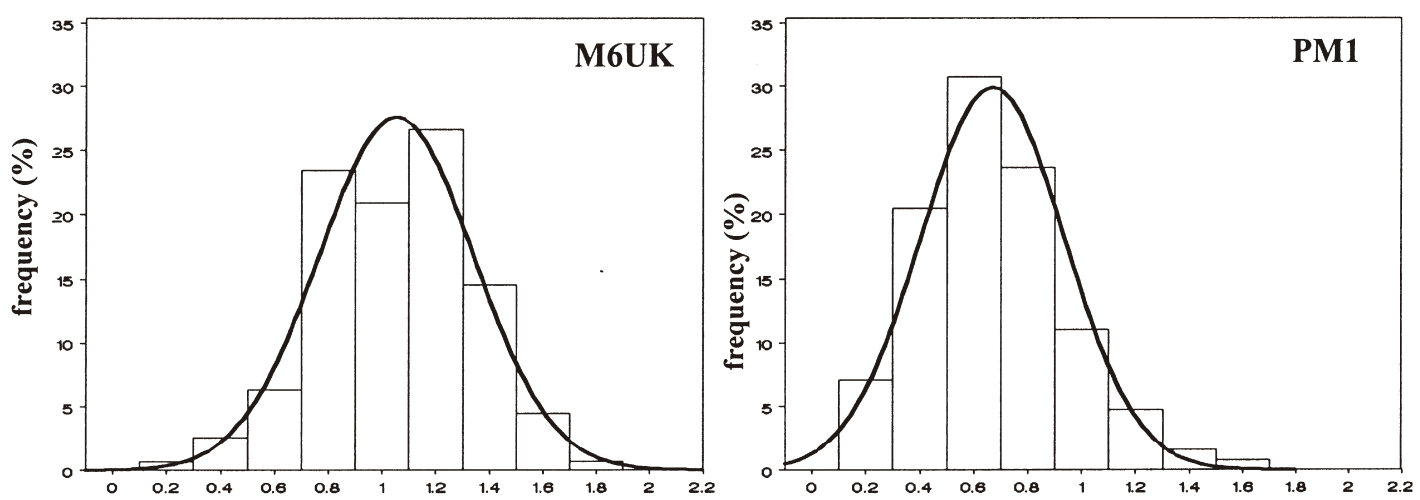

average nicotine uptake $\left(\mathrm{mg} \mathrm{cig}^{-1}\right)$

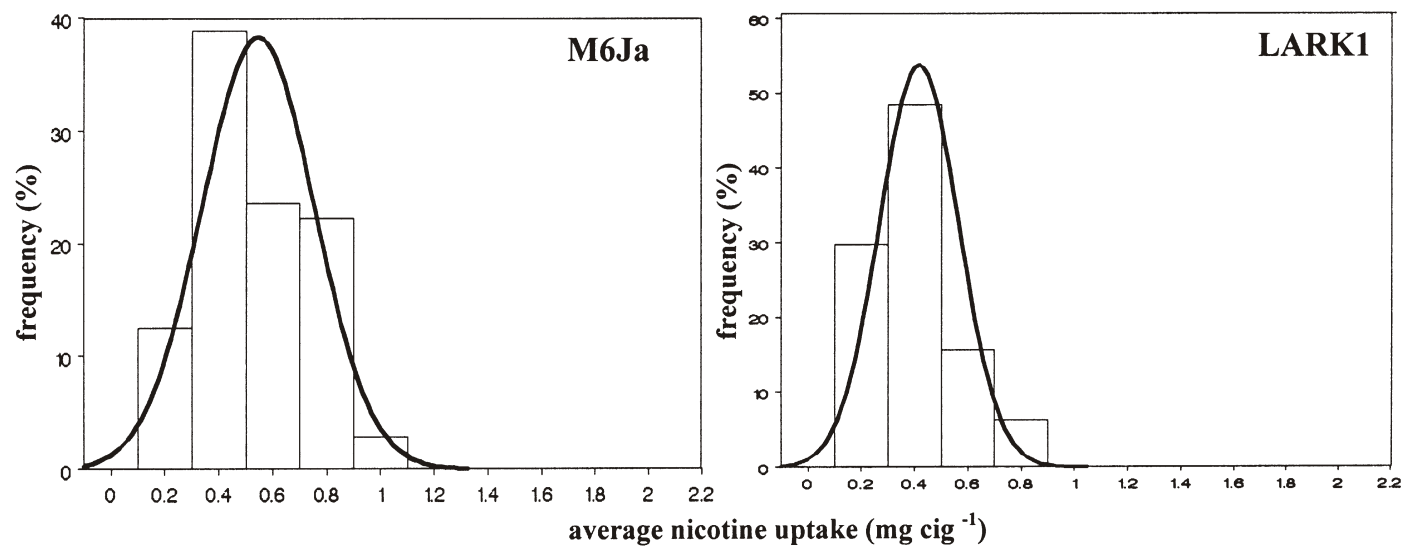

Figure 2. Normal distributions fitted to nicotine uptake from a clinical study for M6UK, M6Ja, PM1, and LARK1

Table 2. Determination of machine-smoking protocols reflecting human smoking behaviour (selected smoking protocol variables, nicotine uptake (from clinical study), modeled nicotine and measured (= "validated") nicotine yields are given)

\begin{tabular}{|c|c|c|c|c|c|c|c|c|}
\hline \multirow[b]{2}{*}{ Cigarette } & \multirow{2}{*}{$\begin{array}{l}\text { Distribution } \\
\text { parameter }\end{array}$} & \multirow{2}{*}{$\begin{array}{c}\text { Protocol } \\
\text { name }\end{array}$} & \multirow{2}{*}{$\begin{array}{l}\text { Puff volume } \\
\left.(\mathrm{mL} \mathrm{cig})^{-1}\right)^{\text {a }}\end{array}$} & \multirow{2}{*}{$\begin{array}{l}\text { Puff duration } \\
\left(\mathrm{s} \mathrm{cig}^{-1}\right)^{\mathrm{b}}\end{array}$} & \multirow{2}{*}{$\begin{array}{c}\text { Puff frequency } \\
\left(\mathrm{min}^{-1}\right)^{\mathrm{c}}\end{array}$} & \multicolumn{3}{|c|}{ Nicotine $\left(\mathrm{mg} \mathrm{cig}^{-1}\right)$} \\
\hline & & & & & & Target (uptake) ${ }^{d}$ & Modeled (yield) ${ }^{e}$ & Measured (yield) ${ }^{f}$ \\
\hline \multirow[t]{3}{*}{ M6UK } & $10^{\text {th }}$ perc. & LOW & 26 & 0.9 & 2.0 & 0.7 & 0.7 & 0.6 \\
\hline & mean & MEDIUM & 50 & 1.4 & 1.8 & 1.1 & 1.1 & 1.1 \\
\hline & $90^{\text {th }}$ perc. & $\mathrm{HIGH}$ & 67 & 1.7 & 1.9 & 1.4 & 1.4 & 1.4 \\
\hline \multirow[t]{3}{*}{ M6Ja } & $10^{\text {th }}$ perc. & LOW & 16 & 0.6 & 0.9 & 0.2 & 0.2 & 0.2 \\
\hline & mean & MEDIUM & 39 & 1.1 & 1.0 & 0.5 & 0.5 & 0.5 \\
\hline & $90^{\text {th }}$ perc. & $\mathrm{HIGH}$ & 55 & 1.5 & 1.2 & 0.8 & 0.8 & 0.8 \\
\hline \multirow[t]{3}{*}{ PM1 } & $10^{\text {th }}$ perc. & LOW & 29 & 0.9 & 3.6 & 0.3 & 0.3 & 0.4 \\
\hline & mean & MEDIUM & 56 & 1.5 & $10^{g}$ & 0.7 & $0.7^{\mathrm{g}}$ & g \\
\hline & $90^{\text {th }}$ perc. & $\mathrm{HIGH}$ & 67 & 1.7 & $18^{9}$ & 1.0 & $0.8^{g}$ & g \\
\hline \multirow[t]{3}{*}{ LARK1 } & $10^{\text {th }}$ perc. & LOW & 29 & 0.9 & 3.0 & 0.3 & 0.2 & 0.3 \\
\hline & mean & MEDIUM & 55 & 1.4 & 2.5 & 0.4 & 0.4 & 0.6 \\
\hline & $90^{\text {th }}$ perc. & $\mathrm{HIGH}$ & 73 & 1.7 & 2.7 & 0.7 & 0.7 & 0.8 \\
\hline
\end{tabular}

a Taken from topography smoking data.

${ }^{\mathrm{b}}$ Estimated with linear regression.

${ }^{\mathrm{c}}$ Found iteratively with the nicotine proportion method in Eqn. [3].

d Uptake from clinical study, used as target value for the nicotine proportion method.

${ }^{\text {e }}$ Estimated with the nicotine proportion method (Eqn. [3]).

${ }^{f}$ Measured in the laboratory for validation purpose.

${ }^{g}$ Reliable estimation of nicotine yield (and thus, validation of the protocol) not possible. See discussion of the model.

were corrected (puff volume: $5 \%$ decrease, and puff duration: increase by $500 \mathrm{~ms}$ ). Only the intercept of the corrected regression line was different from the uncorrected data regression (Figure 4, dotted line), while the slope remained unchanged. It is clear, however, that the correct puff durations would be expected to be higher. c) Puff frequency and puff count: These parameters of the smoking protocols were estimated with Eqns. [3] and [4] (nicotine proportion method) and except for puff volume $_{\text {hum }}$ and puff duration ${ }_{\text {hum }}$, the input values used in these equations are independent from the topography data. 

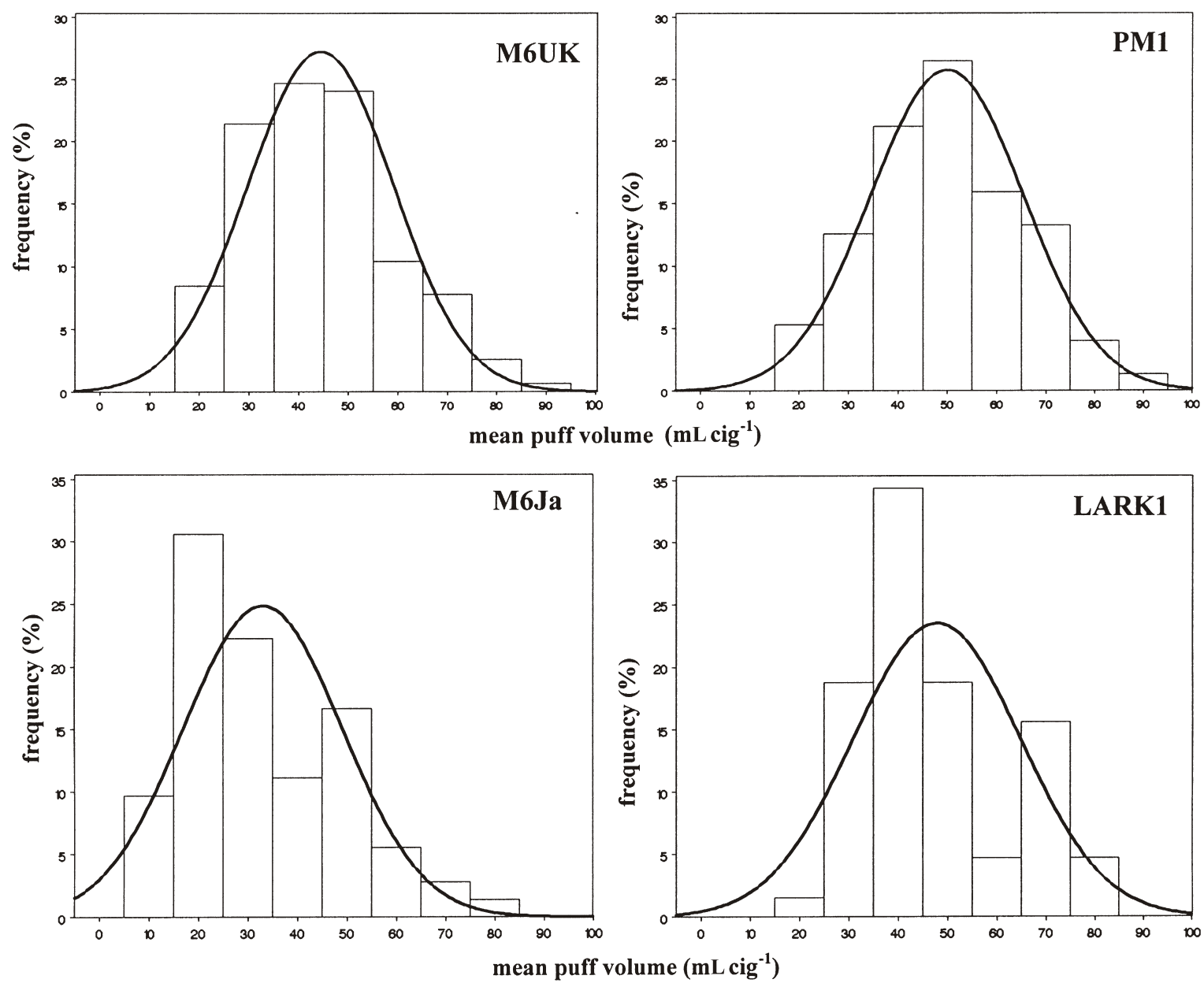

Figure 3. Normal distributions fitted to mean puff volumes from topography data for M6UK, M6Ja, PM1, and LARK1

In conclusion, the possible inaccuracy of the CReSSMicro $^{\mathrm{TM}}$ device has little effect on the validity of the model itself, and the modelled protocols should indeed reflect a true picture of human puffing behaviour. Furthermore, the agreement between smoking topography data and nicotine excretion data (see below) supports the accuracy of the CReSSMicro $^{\mathrm{TM}}$ device. However, the bias of the CReSSMicro ${ }^{\mathrm{TM}}$ device should be further investigated and the exact values reported in this study need further validation.

\section{Technical limitations of the validation procedure} regarding the use of protocols on a standard Borgwaldt Smoking Machine

For some of the modelled smoking protocol variables the 20-port Borgwaldt smoking machine had to be operated in a special mode and beyond the range of its standard (ISO) use. Recordings of the pressure profile at the suction port of the smoking machine confirmed that the puff duration as well as the bell shaped puff profile could be realized for the majority of all samples collected on filters. However, for the sampling with wash bottles or with cartridges, a tendency for longer puff durations (compared to the target duration) was observed and the profile became slightly asymmetric due to the dead volume and the resistance to draw.

In order to use the machine at the higher puff frequencies, the smoking machine carrousel rotation time had to be up to 3.7 times faster than for ISO conditions. As a result, for the estimated puff durations and puff volumes, the highest possible puff frequency value was $3.4-3.8 \mathrm{~min}^{-1}$.

\section{Influence of different ethnic origin}

According to the cigarette design parameters reported in Table 1, the UK and the Japanese versions of the Marlboro cigarettes are almost identical. In fact, they only differ slightly in the tobacco weight (7\% higher in M6Ja) and filter length (7\% lower in M6Ja). Nevertheless, the puff volumes, and thus the estimated puff durations are clearly lower in Japan than in the UK. For example, the mean puff volume, from the topography distribution, was $33.0 \mathrm{~mL}$ for M6Ja and $44.4 \mathrm{ml}$ for M6UK. Apart from the topography data, the urinary excretion data (i.e. nicotine uptake) follow the same pattern. According to the nicotine uptake distributions (Figure 3, Table 2), the mean nicotine uptake of M6Ja is smaller $\left(0.5 \mathrm{mg} \mathrm{cig}^{-1}\right)$ than that of M6UK $\left(1.1 \mathrm{mg} \mathrm{cig}^{-1}\right)$. In other words, it can be concluded that Japanese smokers smoked the Marlboro cigarettes differently than UK smokers do. The agreement between smoking topography data and nicotine excretion data also supports the accuracy of the CReSSMicro ${ }^{\mathrm{TM}}$ device.

No published information on smoking topography in Asian and Caucasian smokers seems to be available. However, ethnic differences in smoking topography have been reported for other cases. African Americans for example 


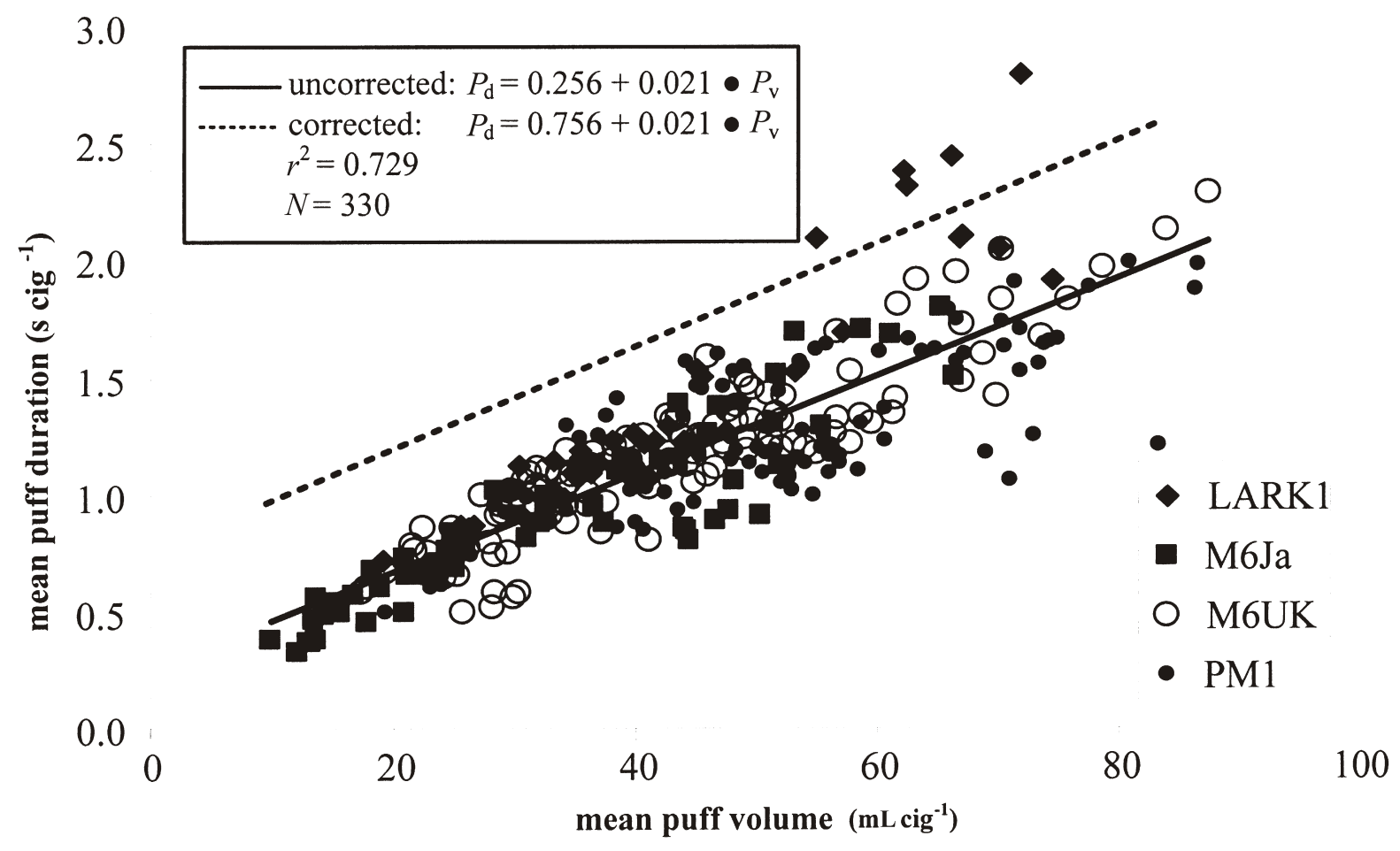

Figure 4. Regression of mean puff duration and mean puff volume, for M6UK, M6Ja, PM1, and LARK1 (for corrected data see discussion)

were reported to have shorter exhalation periods and have higher nicotine intake than Caucasians $(10,24)$ and daily total puff volume is significantly less in African American women compared to Caucasians women (1).

We observed a clear tendency in Japanese smokers towards larger "butt lengths" compared to UK smokers. This suggests that mean urinary nicotine uptake per cigarette may be lower in Japanese smokers, because of larger butt length, assuming there are no or little differences in smoking behaviour (i.e. topography) and cigarette design.

\section{Evaluation of the model}

For 10 out of 12 modelled protocols a very good agreement between the theoretically estimated (i.e. modelled) and the validated measured nicotine yield was observed (Table 2). However, it was not possible to obtain realistic puff frequencies using the nicotine proportion method for the MEDIUM and the HIGH protocols of the PM1 cigarette. For the PM1 MEDIUM protocol the modelled puff frequency was $10 \mathrm{~min}^{-1}$ (at a target nicotine yield of $0.7 \mathrm{mg}$ $\mathrm{cig}^{-1}$ ) and for the PM1 HIGH protocol it was not possible to reach the target value: the target yield was $1.0 \mathrm{mg} \mathrm{cig}^{-1}$, whereas the highest calculated nicotine yield was $0.8 \mathrm{mg}$ $\mathrm{cig}^{-1}$ at a modelled puff frequency of $18 \mathrm{~min}^{-1}$. For physiologically reasons these modelled puff frequencies of the two protocols are unrealistic.

The exact reasons for the limitation of the model regarding the PM1 MEDIUM and HIGH protocols remain unclear and may be due to topography parameters not included in our model (e.g., butt length, vent blocking). As we had no information from human topography regarding these variables, any assumptions at this point would be rather speculative.
Recently, HAMMOND et al. (15) compared four different smoking protocols (ISO, Canadian, Massachusetts and Compensatory), and differences between the four smoking protocols with human smoking behaviour. They programmed a smoking machine with mean puff volumes and mean puff frequencies using a CReSSMicro ${ }^{\mathrm{TM}}$ device during a field study. (Estimation of puff duration was not explained, probably these values were set by machine or they used fixed values.) This protocol was called "Human Mimic Smoking" protocol. Of the four smoking protocols evaluated, only the yields for the Canadian protocol were close to the levels of smoke constituents using the Human Mimic Smoking protocol. They conclude that "no single nicotine yield can adequately characterize the distribution of nicotine uptake within a single brand" and "no single machine testing regimen is capable of predicting individual exposure". The finding that individual exposure cannot be estimated by one smoking protocol is not surprising, but it is a conclusion followed from smoking topography variability and it is accounted for in our approach, using three different smoking protocols (LOW, MEDIUM, HIGH) based on the percentiles of normal distribution. As these distributions represent the population variability, our protocols effectively represent human puffing behaviour. The Human Mimic Smoking protocol (15) cannot be compared directly with our modelled protocols, as only puff volumes and puff frequencies seem to have been considered. In our modelling approach we used puff volumes, puff durations and puff frequencies in an integrated nicotine proportion method, resulting in a very good agreement between measured nicotine yield and nicotine uptake found in the clinical study. 


\section{CONCLUSION}

Excluding the two protocols which could not be modelled adequately (PM1 MEDIUM and PM1 HIGH), the average set of smoking parameters for the three protocols are: LOW: $25 \mathrm{~mL} \cdot \mathrm{cig}^{-1}$ puff volume, $0.8 \mathrm{~s} \cdot \mathrm{cig}^{-1}$ puff duration, $2.4 \mathrm{~min}^{-1}$ puff frequency; MEDIUM: $48 \mathrm{~mL} \cdot \mathrm{cig}^{-1}$ puff volume, $1.3 \mathrm{~s} \cdot \mathrm{cig}^{-1}$ puff duration, $1.8 \mathrm{~min}^{-1}$ puff frequency; HIGH: $65 \mathrm{~mL} \cdot \mathrm{cig}^{-1}$ puff volume, $1.6 \mathrm{~s} \cdot \mathrm{cig}^{-1}$ puff duration, $1.9 \mathrm{~min}^{-1}$ puff frequency. Given that our approach was based on the puff volumes and the puff duration from human smoking topography data, and the puff frequency is indirectly proportional to nicotine uptake from human smokers, these protocols can be considered to effectively reflect human smoking behaviour.

Smokers exhibit different and varied smoking patterns, which affect smoke delivery and exposure by altering smoking topography, e.g., puff volume, puff duration, interpuff interval, butt length and blocking of ventilation holes. Our modelling approach can be used to derive smoking protocols reflecting a wide range of human smoking behaviour, supported by both human smoking topography and nicotine uptake distributions determined in clinical studies. The advantage of this modelling method for future cigarette testing is that cigarette smoke can be generated that is more reflective of human puffing behaviour. Thus, laboratory assays can be applied to cigarette smoke, when the focus is a more meaningful examination of the smoke matrix in the context of evaluating reduced exposure or risk products.

\section{ACKNOWLEDGEMENTS}

Dr. Wolf Reinighaus contributed with many fruitful ideas to the initiation of this project. An important part of the models and equations used in this study are based on ideas and initial developments of Dr. Bill Dwyer (Philip Morris USA, Virginia). Data used for this study were obtained from different studies carried out at Philip Morris Research Laboratories GmbH (Germany) and Philip Morris Products SA (Switzerland). We would like to thank all technicians and scientists who participated in these studies, especially Dr. Jörg Diekmann for independently validating the modelled protocols on the smoking machine in the laboratory and to Claire Martine Leroy for her help on the database. Dr. Jean-Jacques Piadé (Philip Morris Products SA, Research \& Development, Switzerland) improved earlier versions of this manuscript.

\section{REFERENCES}

1. Ahijevych, K., H. Wee, and J. Clarke: Levels of cigarette availability and exposure in black and white women and efficient smokers; Pharmacol. Biochem. Behav. 77 (2004) 685-693.

2. Ashton, H., R. Stepney, and J.W. Thompson: Self titration by cigarette smokers; Brit. Med. J. 2 (1997) 357-360.

3. Baker, R.R.: The development and significance of standards for smoking-machine methodology; Beitr. Tabakforsch. Int. 20 (2002) 23-41.
4. Benowitz, N.L. and P. Jacob: Daily intake of nicotine during cigarette smoking; Clin. Pharmacol. Ther. 35 (1984) 499-504.

5. Benowitz, N.L. and P. Jacob: Nicotine and carbon monoxide intake from high- and low-yield cigarettes; Clin. Pharmacol. Ther. 36 (1984) 264-270.

6. Bridges, R.B., J.G. Combs, J.W. Humble, J.A. Turbek, and N.J. Haley: Puffing topography as a determinant of smoke exposure; Pharmacol. Biochem. Behav. 37 (1990) 29-39.

7. Bridges, R.B., J.W. Humble, J.A. Turbek, and S.R. Rehm: Smoking history, cigarette yield and smoking behavior as determinants of smoke exposure; Eur J Respir. Dis. 69 (1986) 129-137.

8. Byrd, G.D., R.A. Davis, W.S. Caldwell, J.H. Robinson, and J.D. deBethizy: A further study of FTC yield and nicotine absorption in smokers; Psychopharmacology 139 (1997) 291-299.

9. Byrd, G.D., J.H. Robinson, W.S. Caldwell, and J.D. deBethizy: Comparison of measured and FTC-predicted nicotine uptake in smokers; Psychopharmacology 122 (1995) 95-103.

10. Clark, P.I., S. Gautam, and L.W. Gerson: Effect of menthol cigarettes on biochemical markers of smoke exposure among black and white smokers; Chest 110 (1996) 1194-1198.

11. Counts, M.E., M.J. Morton, S.W. Laffoon, R.H. Cox, and P.J. Lipowicz: Smoke composition and predicting relationships for international commercial cigarettes smoked with three machine-smoking conditions; Regul. Toxicol. Pharmacol. 41 (2005) 185-227.

12. Dwyer, R.W., P. Chen, and R. Wasyk:. A mathematical scheme for calculating flows and pressure drops in lit and unlit cigarettes; Beitr. Tabakforsch. Int. 19 (2001) 189-203.

13. Gori, G.B. and C.J. Lynch: Analytical cigarette yields as predictors of smoke bioavailability; Regul. Toxicol. Pharmacol. 5 (1985) 314-326.

14. Hammond, D., G.T. Fong, K.M. Cummings, and A. Hyland: Smoking topography, brand switching, and nicotine delivery: results from an in vivo study; Cancer Epidemiol. Biomarkers Prev. 14 (2005) 1370-1375.

15. Hammond, D., G.T. Fong, K.M. Cummings, R.J. O'Conner, G.A. Giovino, and A. McNeill: Cigarette yields and human exposure: A Comparison of alternative testing regimens; Cancer Epidemiol. Biomarkers Prev. 15 (2006) 1495-1501.

16. Hearn, J. and F. Yang: Evaluation of CReSSMicroTM smoking measurements devices; Communication to $\mathrm{S}$. Wrenn, R. Lee and S. Yang., personal communication, Philip Morris USA, 2004.

17. International Organization for Standardization: Routine analytical cigarette-smoking machine - Definitions and standard conditions; ISO 3308, 1991.

18. Jarvis, M.J., R. Boreham, P. Primatesta, C. Feyerabend, and A. Bryant: Nicotine yield from machinesmoked cigarettes and nicotine intakes in smokers: Evidence from a representative population survey; J. Natl. Cancer Inst. 93 (2001) 134-138.

19. Kassel, J.D., J.E. Greenstein, D.P. Evatt, M.C. Wardle, M.C. Yates, J.C. Veilleux, and T. Eissenberg: Smoking topography in response to denicotinized and 
high-yield nicotine cigarettes in adolescent smokers; J. Adolesc. Health 40 (2007) 54-60.

20. Kolonen, S., J. Tuomisto, P. Puustinen, and M.M. Airaksinen: Smoking behavior in low-yield cigarette smokers and switchers in the natural environment; Pharmacol. Biochem. Behav. 40 (1991) 177-180.

21. Kozlowski, L.T., W.S. Rickert, M.A. Pope, J.C. Robinson, and R.C. Frecker: Estimating the yield to smokers of tar, nicotine and carbon monoxide from the lowest yield ventilated filter cigarettes; Brit. J. Addict. 77 (1982) 159-165.

22. Moody, P.M.: The relationships of quantified human smoking behavior and demographic variables; Soc. Sci. Med. 14 A (1980) 49-54.

23. Nil, R. and K. Bättig: Separate effects of cigarette smoke yield and smoke taste on smoking behavior; Psychopharmacology 99 (1989) 54-59.

24. Pérez-Stable, E., B. Herrera, P.I. Jacob, and N.L. Benowitz: Nicotine metabolism and intake in black and white smokers; J. Am. Med. Assoc. 280 (1998) 152-156.

25. Pillsbury, H.C.: Review of the Federal Trade Commission: Method for determining cigarette tar and nicotine yield; NCI Expert Committee, U.S. Department of Health and Human Services, National Institutes of Health, Monograph 7, Bethesda, MD, 1996.

26. Pillsbury, H.C., C.C. Bright, R.J. O'Conner, and F.W. Irish: Tar and nicotine in cigarette smoke; J. Assoc. Off. Anal. Chem. 52 (1969) 458-462.

27. Rickert, W.S. and J.C. Robinson: Estimating the hazards of less hazardous cigarettes, II: Study of cigarette yields of nicotine, carbon monoxide, and hydrogen cyanide in relation to levels of cotinine, carboxyhemoglobin and thiocynate in smokers; J Toxicol. Environ. Health 7 (1981) 391-403.

28. Roethig, H.J., R.D. Kinser, R.W. Lau, R.A. Walk, and N. Wang: Short-term exposure evaluation of adult smokers switching from conventional to firstgeneration electrically heated cigarettes during controlled smoking; J. Clin. Pharmacol. 45 (2005) 133-145.
29. Russell, M.A.H., M.J. Jarvis, R. Iyer, and C. Feyerabend: Relation of nicotine yield of cigarettes to blood concentrations in smokers; Brit. Med. J. 280 (1980) 972-976.

30. Rustemeier, K. and J.J. Piadé: Determination of nicotine in mainstream and sidestream cigarette smoke; in; Analytical determination of nicotine and related compounds and their metabolites, edited by $\mathrm{J}$. W. Gorrod and P.J.I. Peyton, Elsevier, Amsterdam, 1999, pp. 489-530.

31. Strasser, A.A., R.L. Ashare, L.T. Kozlowski, and W.B. Pickworth: The effect of filter vent blocking and smoking topography on carbon monoxide levels in smokers; Pharmacol. Biochem. Behav. 82 (2005) 320-329.

32. Watson, C., J. McCraw, G. Polzin, D. Ashley, and D. Barr: Development of a method to assess cigarette smoke intake; Environ. Sci. Technol 38 (2004) 248-253.

33. Woodman, G., S.P. Newman, D. Pavia, and S.W. Clarke: Response and acclimatisation of symptomless smokers on changing to a low tar, low nicotine cigarette; Thorax 42 (1987) 336-341.

34. Woodward, M. and H. Tunstall-Pedoe: Self-titration of nicotine: Evidence from the Scottish Heart Health Study; Addiction 88 (1993) 821-830.

35. Zacny, J.P. and M.L. Stitzer: Cigarette brandswitching: Effects on smoke exposure and smoking behavior; J. Pharmacol. Exp. Ther. 246 (1988) 619-627.

Address for correspondence:

Hans-Jörg Urban

Philip Morris International

Philip Morris Product SA

Research \& Development

Quai Jeanrenaud 56

2000 Neuchâtel

Switzerland

E-mail: Hans-Jörg.Urban@pmintl.com 